\title{
Complications of botulinum toxin application: differences between hemifacial spasm and post-facial palsy synkinesis
}

\author{
M. Aysen Cakmak · Sevki Sahin • Nilgun Cinar • \\ Sibel Karsidag
}

Received: 30 January 2014/ Accepted: 25 February 2014/Published online: 20 March 2014

(C) Belgian Neurological Society 2014

\section{Dear Editor,}

Although hemifacial spasm (HFS) and post-facial palsy synkinesis (PFPS) are two different entities with different underlying causes, both share an effective treatment option: botulinum neurotoxin (BoNT). Its mechanism is temporary blocking of the presynaptic release of acetylcholine in neuromuscular junction which lasts 3-6 months [1]. Herein, we report the complications of BoNT use in HFS and PFPS.

A retrospective analysis was conducted using the medical records of well documented $30 \mathrm{HFS}$ and 20 PFPS patients. Botilinum toxin A (Botox ${ }^{\circledR}$ ) was reconstituted with $2 \mathrm{ml}$ of preservative free $0.9 \%$ saline solution to yield toxin in a concentration of 5 units per $0.1 \mathrm{ml}$. Selected muscles were orbicularis oculi, corrugator supercilii, frontalis in superior facial area, zygomaticus, orbicularis oris, mentalis in middle and inferior facial area. Statistical analysis was performed using Mann-Whitney $U$ test.

Hemifacial spasm group consisted of 17 females and 3 males with a mean age of $47 \pm 11$ years. The mean duration of symptoms was $17 \pm 8$ months. In three

\footnotetext{
M. A. Cakmak $(\bowtie) \cdot$ S. Sahin · N. Cinar $\cdot$ S. Karsidag

Department of Neurology, Faculty of Medicine, Maltepe

University, 34843 Istanbul, Turkey

e-mail: aysenunsal@yahoo.com

S. Sahin

e-mail: drsahin@gmail.com

N. Cinar

e-mail: nilguncinar@gmail.com

S. Karsidag

e-mail: karsidags@yahoo.com
}

patients a dolicho-ectatic basilar artery was founded on the symptomatic side in brain magnetic resonance imaging. All the patients received 3-9 BoNT injections. Mean BoNT dose was $66 \pm 56$ U. Of HFS patients, $34 \%$ developed complications: ptosis $24 \%$ and orbicularis oris paralysis $10 \%$.

Post-facial palsy synkinesis group consisted of 18 females and 2 males with a mean age of $59.3 \pm 12$ years. The mean duration of symptoms was $19 \pm 8$ months. A medical history of Bell's palsy was present in 12 patients. All of the patients received 3-7 BoNT injections. Mean BoNT dose was $53 \pm 24 \mathrm{U}$. Complications occurred in $77 \%$ of PFPS patients consecutively: ptosis $33 \%$, dry eyelagophthalmos $11 \%$, orbicularis oris paralysis $11 \%$, eye and mouth complications together $22 \%$. The difference of complication rates between the two groups was statistically significant ( $p: 0.04)$.

Based on our results, it appears that complications of BoNT are more frequent in PFPS. This may be due to the previous muscle weakness and axonal damage in PFPS [2]. In conclusion, choosing hyperactive muscle for injections and lower doses of BoNT in PFPS may reduce complication ratios.

Conflict of interest Mirac Aysen declares no conflict of interest.

\section{References}

1. Ward AB, Molenaers G, Colosimo C, Berardelli A (2006) Clinical value of botulinum toxin in neurological indications. Eur J Neurol 13(4):20-26

2. Borodic GE, Pearce LB, Cheney M et al (1993) Botulinum A toxin for treatment of aberrant facial nerve regeneration. Plast Reconstr Surg 91(6):1042-1045 